\title{
Level of knowledge, prevention practice, and predictors towards stroke among diabetic and hypertensive patients having a follow up at University of Gondar Comprehensive Specialized Referral Hospital, Northwest Ethiopia. A cross-sectional study
}

\author{
Abebe Basazn Mekuria, Zemene Demelash Kifle *, Abreham Degu Melak \\ Department of Pharmacology, School of Pharmacy, College of Medicine and Health Science, University of Gondar, Gondar, Ethiopia
}

\section{A R T I C L E I N F O}

\section{Keywords:}

Knowledge

Stroke

Practice

Hypertension

Diabetic mellitus

\begin{abstract}
A B S T R A C T
Background: Because of poor health care service delivery and a low level of public awareness of the disease the incidence and disability rate of stroke has been increased. The study aimed to assess the knowledge, prevention practice, and associated socio-demographic factors towards stroke among hypertensive and diabetic patients. Method: Cross-sectional based study design was applied on hypertensive and diabetic patients after they were selected with a simple random sampling technique. The data were collected with a structured intervieweradministered questionnaire.

Result: All the computed 382 respondents responded with a response rate of $100 \%$. Among the participants $52.36 \%$ were males. The finding showed that the respondents had $36.65 \%$ and $42.67 \%$ good knowledge and prevention practice of stroke respectively. The associated demographic factors with good knowledge of stroke were urban residency [AOR, (95\% CI), 4.54 (2.23-9.25)], Age <50 years [AOR, 95\% CI; 1.80 (1.06-3.05)], educational status [AOR, 95\% CI; 2.78 (1.45-5.31)], monthly income [AOR.95\% CI; 1.98 (1.15-3.40)] and >5 years' duration of the disease [AOR, 95\% CI; 1.94 (1.15-3.27)]. Similarly, urban residency [AOR, (95\% CI); 1.91 (1.06-3.43)], being educated [AOR, 95\% CI; 2.98 (1.67-5.31) monthly income [AOR, 95\% CI; 2 (1.20-3.32)] and medical condition become hypertension (HTN) with Diabetes mellitus (DM) [AOR, 95\% CI; 2.068 (1.20-3.57)] were strongly associated factors with good prevention practice of stroke. However, the occupational status being Farmer [AOR, 95\% CI; $0.31(0.107-0.91)]$ was preventive against good prevention practice of stroke.

Conclusion: The study showed that the respondent's level of knowledge and prevention practice towards stroke was limited.
\end{abstract}

\section{Introduction}

According to the World Health Organization (WHO) definition of stroke as 'rapidly developed clinical signs of focal (or global) disturbance of cerebral function, lasting more than $24 \mathrm{~h}$ or leading to death, with no apparent cause other than of vascular origin'. ${ }^{1}$ These cerebrovascular diseases affecting the brain can be either ischemic (85\%) or hemorrhagic (15\%) type. Ischaemic stroke is caused by interruption of the blood supply to a part of the brain resulting in a sudden loss of functioning, while hemorrhagic stroke is attributed to an abnormal vascular structure/rupture. ${ }^{2}$

This sharply raising cardiovascular accident can be attributed to a range of risk factors i.e. modifiable and non-modifiable. Though the nonmodifiable risk factors have their contribution to stroke emergency, modifiable life events like Hypertension, diabetes mellitus, heart diseases, hypercholesterolemia, physical inactivity, smoking, and excessive alcohol use have been the major attributes. Hypertension is the most common of all precipitators. ${ }^{3-9}$

Patients attacked with stroke events, manifest different signs and symptoms of neurologic dysfunction like one side body weakness, hemiparesis, aphasia, loss of vision/double, severe headache, vertigo, or falling. The abrupt onset and the duration of the symptoms are determined through history. Immediate recognition of, and response to, stroke signs and symptoms are essential to an optimal outcome. In

\footnotetext{
* Corresponding author.

E-mail address: zeme2010@gmail.com (Z.D. Kifle).
} 
addition to the clinical diagnosis, neurologic imaging (MRI or CT scan) can have an important role in the early identification of the stroke type and affected part. ${ }^{10}$

Current guidelines recommend early recognition and reperfusion ( $<4.5 \mathrm{~h}$ from onset) with IV tPA to reduce the ultimate disability caused by an ischemic stroke. However, patients with hemorrhagic stroke are best treated with surgical interventions to reduce mortality owing to rebleeding. ${ }^{10,11}$ Public awareness of the warning signs is important to recognize an acute stroke thereby providing rapid hospitalization. Risk factors knowledge is also equally important, to raise both primary and secondary prevention patterns of stroke. ${ }^{12}$

Despite global age-standardized mortality rates of stroke showed a sharp decline from 1990 to 2016, its prevalence rate and its burden were still high. ${ }^{13}$ Reports showed that 80.1 million prevalent cases, 5.5 million deaths, and 116.4 million DALYs of stroke in the world were recorded at the end of 2016. The burden of stroke in developing countries especially SSA is remaining high. ${ }^{10,14}$

The increased prevalence of DM also contributes up to $30 \%$ incidence to stroke events. ${ }^{13,15,16}$ By the year 2019, the estimated average global prevalence of DM was $9.3 \%$ (463 million). This prevalence of DM is projected to be $10.2 \%$ by 2030 . This could be the cause for more than one-third of stroke prevalent cases. ${ }^{17}$

As a result of poor awareness and practice among high-risk groups, the incidence of cerebrovascular disease has been tremendously increased in developing countries including Ethiopia. So that considering it as a major public health concern, assessing the awareness and practice status of these groups can have a paramount advantage to set a corrective action.

Because of the late presentation of the patients ( $>4.5 \mathrm{hrs}$ ) and poor standard of hospitalized care, the treatment outcome becomes worsen eventually mortality and disability have been increased in Ethiopia. ${ }^{5,18,19}$ So that upon considering health education as the major concern of the health care system, identifying the gaps first is necessary.

Even there are inadequate studies done in Ethiopia that can directly show the knowledge and practice level of HTN and DM patients towards stroke so that it could be used as a reference for future researchers. Therefore, this study aimed to assess the level of knowledge, prevention practice, and associated socio-demographic factors towards stroke among Hypertensive and Diabetic patients having a follow up at University of Gondar Comprehensive Specialized Referral Hospital, Northwest Ethiopia.

\section{Methods}

\subsection{Study design}

An institution-based cross-sectional study was conducted to assess the level of knowledge, prevention practice, and associated sociodemographic predictors towards stroke among hypertensive and diabetic patients attending a chronic ambulatory care clinic at the University of Gondar Comprehensive Specialized Referral Hospital, Northwest Ethiopia.

\subsection{Study area and period}

The study was conducted at the University of Gondar Comprehensive Specialized Hospital, Chronic ambulatory care clinic from May to September 2021. University of Gondar Comprehensive Specialized Hospital is found at Gondar town in Amhara region, $727 \mathrm{~km}$ away from Addis Ababa, the capital city of Ethiopia. It provides hospital care services for more than seven million people both in and outside the town. In this hospital, more than 5000 hypertensive and diabetic patients have been enrolled to get the chronic health care service.

\subsection{Population}

\subsubsection{Source population}

All adult hypertensive and diabetic patients who attended and registered for life-long treatment at chronic ambulatory care and treatment clinic were the source population.

\subsubsection{Study population}

All adult hypertensive and diabetic patients who attended and registered at chronic ambulatory care and treatment clinic at University of Gondar Comprehensive Specialized Hospital were the study population.

\subsection{Inclusion and exclusion criteria}

\subsubsection{Inclusion criteria}

All HTN and or DM patients age $\geq 18$ years, who have been enrolled in the CACC for at least 6 months at University of Gondar Comprehensive Specialized Hospital and those who have the willingness to take written informed consent by themselves were included in the study.

\subsubsection{Exclusion criteria}

Any HTN and/or DM patients who have hearing problems, speaking problems, critical illness, and are mentally ill but had a follow-up in this Hospital were excluded from the study.

\subsection{Sample size determination}

The single population proportion formula was used with the assumption of $95 \%$ confidence interval, $5 \%$ margin of error, and $50 \%$ proportion of hypertensive and diabetic patients who have good knowledge and practice towards stroke since there was no similar study in the area.

$\mathrm{n}=[(\mathrm{Z} \alpha / 2) 2 \times \mathrm{P}(1-\mathrm{P})] / \mathrm{W}^{2}$

Where, $\mathrm{n}=$ Initial sample size

$\mathrm{Z} \alpha / 2=$ Precision level $=1.96$

$\mathrm{P}=$ Proportion $=0.5$

$\mathrm{W}=$ Marginal error $=5 \%$

The final sample size with $10 \%$ for possible incomplete data was 422 . For the sake of accuracy, the sample size determination was generated using Epi-info version 7.2.2.6 as follows. The net calculated sample size was determined with consideration of the correction formula to be feasible.

Correction formula $=\frac{n}{1+\boldsymbol{n} / \boldsymbol{N}}=\frac{422}{1+\frac{422}{4,000}}=382 \mathrm{HTN}$ and or DM patients were included in the study. Finally, the computed sample size was $\mathbf{3 8 2}$.

\subsection{Sampling procedure}

After the subjects were grouped into three strata (i.e. Hypertensive, diabetic and Hypertensive, and Diabetic), 382 subjects were enrolled into the study proportionally from each stratum. There are more than 5000 hypertensive and diabetics patients at University of Gondar Comprehensive Specialized Hospital, Chronic ambulatory Care Clinic. From this, more than 3300 were diabetic patients. Through the application of using a simple random sampling technique, the study participants were selected from those HTN and or DM patients who were registered at the University of Gondar Comprehensive Specialized Hospital, Chronic ambulatory Care Clinic. To get the computed sample size, starting from the first interviewing day, subjects were recruited. 


\subsection{Variables of the study}

\subsubsection{Dependent variable}

$\checkmark$ Level of knowledge

$\checkmark$ Level of prevention practice

\subsubsection{Independent variables}

$\checkmark$ Socio-demographic variables like age, sex, residence, level of education, occupation, employment status, religion, marital status, level of income, medical condition, and duration of the disease condition.

\subsection{Operational definitions}

Level of Knowledge: Respondents that score more or equal to the computed mean knowledge score were graded as having good knowledge, while those with scores less than expected mean knowledge were graded as having poor knowledge.

Level of practice: Respondents that score more or equal to the computed mean practice score were graded as having a good practice, while those with scores less than expected mean practice were graded as having poor practice.

Regular exercise: $20 \mathrm{~min}-30 \mathrm{~min}$ of aerobic exercise such as walking, jogging, swimming for 5-7 days per week. ${ }^{20-22}$

Salt restriction: The daily recommended salt intake is not more than $2.0 \mathrm{~g}$ per day (equivalent to approximately $5.0 \mathrm{~g}$ salt per day. ${ }^{23}$ But if home-prepared spices have salt, restrict not to add more salt. ${ }^{22,24}$

\subsection{Data collection tools and procedures}

A structured face-to-face interviewer-administered questioner was used to collect the data. This interview was conducted at the time of chronic care clinic visits coming for their follow-up by translating the questioners to the language that the patient can understand (Amharic). For the sake of quality of data collection and due to financial constraints, we the investigators were participated to collect the data under the supervision of our Advisor and the subjects were selected based on the inclusion and exclusion criteria; the interview was undertaken after providing well information on the objective of the study for those study subjects who have the willingness to take the informed consent. The questioner was prepared in consideration and reviewing other similar international literature. The Data collection questionnaire has 6 subparts; socio-demographic, knowledge regarding the general concept, sign and symptom, risk factor, prevention methods, and practice.

\subsection{Data quality control}

To maintain data quality, an appropriate and valid data extraction tool was used. The data collection tool was pre-tested for consistency and completeness of data items on $5 \%$ of patients at the same hospital. For good consistency of data collection, the investigators and the adviser met three days before commencing the interview to retrieve the data and to take a common understanding of the questioner.

\subsection{Data processing and analysis}

After the completion of data collection, the consistency and completeness of each questionnaire were assessed and coded before data entry into the software system. The data was entered into an abstraction format prepared in SPSS version 26 for further data analysis; the summary data was presented with descriptive statistics. Then variables analyzed with bivariate logistic regression having P-value $\leq 0.2$ were processed into a multivariate logistic regression analysis system to explore more on the strength of associated factors and the Stroke level of knowledge and practice with $\mathrm{OR} \geq 95 \%$ confidence interval. The criterion for statistical significance was at $P \leq 0.05$. The questioner containing the knowledge part has two alternatives/Yes/No/which can be analyzed as it is. But, questions regarding the prevention practice have five alternatives so that for the sake of analysis it was grouped in two (i.e. good and poor).

\section{Results}

\subsection{Baseline characteristics of the study subjects}

The study sample size was 382 respondents and all were interviewed. Thus, the response rate becomes $100 \%$. Among the participants $52 \%$ of the respondents were male. The respondent's age was ranging from 20 to 92 years (mean $51.51 \pm 16.66$ ). Of the respondents, the majorities $(68.32 \%)$ were urban residents and $62.11 \%$ were married. The majority of the respondents were married $(62.11 \%)$ and educated $(64.4 \%)$. Regarding their medical condition, $46.34 \%$ were diabetics as shown in Table 1 below.

\subsection{Level of knowledge towards stroke}

Knowledge of stroke is considered regarding the general concepts, signs and symptoms, risk factors, and prevention strategies of stroke. Based on the knowledge assessment tool, the score was ranging from 0 to 39. The mean knowledge score of the respondents was $20.34 \pm 12.7$ (mean \pm SDV).

Participants' having a good level of knowledge of the general concepts, signs, and symptoms, risk factors and prevention strategies were $34.26 \%, 32.21 \%, 41.72 \%$, and $38.41 \%$ respectively. In general, the respondents had $36.65 \%$ good knowledge about stroke as shown in Fig. 1 below.

\subsection{Associated socio-demographic factors to stroke knowledge}

Multivariate logistic regression analysis was done for factors with a P-value of less than 0.2 in bivariate analysis to see the association among variables. Thus in this study age less than 50 years $(\mathrm{AOR}=1.8$; CI:

Table 1

Sociodemographic characteristics of participants.

\begin{tabular}{llll}
\hline Variables & & Frequency & Percentage (\%) \\
\hline Sex & Male & 200 & 52.36 \\
Age & Female & 182 & 47.64 \\
Residence & $<50$ years & 213 & 55.76 \\
& $\geq 50$ years & 169 & 44.24 \\
Religion & Urban & 261 & 68.32 \\
& Rural & 121 & 31.68 \\
Marital status & Orthodox & 241 & 63.09 \\
& Muslim & 79 & 20.68 \\
& Protestant & 62 & 16.23 \\
Educational status & Single & 68 & 17.80 \\
& Married & 237 & 62.04 \\
Occupational status & Divorced & 42 & 10.99 \\
& Windowed & 35 & 9.16 \\
& Unable to read and write & 136 & 35.60 \\
& Able to read and write & 246 & 64.40 \\
& Gov't employee & 96 & 25.13 \\
& House wife & 68 & 17.80 \\
Furation of the disease & Farmer & 74 & 19.37 \\
& Private Employee & 37 & 9.69 \\
Monthly income & Herch years & 78 & 20.42 \\
Medical condition & Merchant & 29 & 7.59 \\
& Other & 240 & 62.83 \\
& $\leq 3000$ & 142 & 37.17 \\
& $>3000$ & 73 & 19.11 \\
& HTN & 177 & 46.34 \\
& DM & 132 & 34.55 \\
& HTN with DM & 46.86 \\
& & 53.14 \\
\hline
\end{tabular}




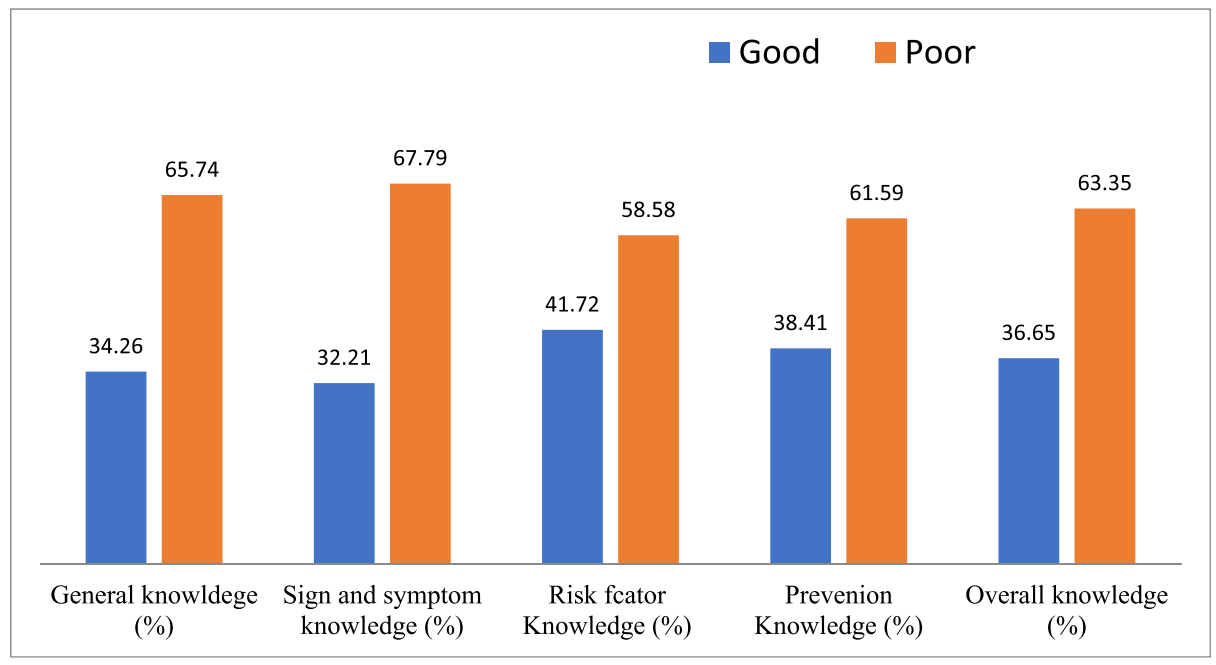

Fig. 1. Respondents Knowledge of stroke.

1.06-3.05), urban residency (AOR $=4.54$; CI, 2.23-9.25), educational level (AOR $=2.78$; CI, 1.45-5.31, monthly income $>3000$ Birr (AOR $=$ 1.98 ; CI, 1.15-3.40), and duration of the disease $>5$ years $(\mathrm{AOR}=1.94$; CI, 1.15-3.27) were the associated factors with a good level of stroke (Pvalue $\leq 0.05$ ) Table 2 .

\subsection{Level of prevention practice towards stroke}

The computed mean prevention practice score of stroke was $26.25 \pm$ 5.25 (mean \pm SDV). The respondents' level of practice to prevent the emergence of stroke among these risky populations was around $42.67 \%$ as shown in Fig. 2 below.

\subsection{Associated socio-demographic factors to stroke prevention practice}

The multivariable analysis ( $\mathrm{p}$-vale $\leq 0.05$ ) showed that good prevention practice of stroke is associated with urban residency (AOR = 1.91; CI: $1.06-3.43$ ), educational level (AOR $=2.98$; CI: 1.67-5.31), monthly income $>3000$ birr (AOR $=2.00$; CI: $1.20-3.32$ ), and medical condition having both HTN and DM (AOR $=2.068$; CI: $1.20-3.57$ ). However, the occupation of being a farmer is the preventive factor against lifestyle modification practice (AOR $=0.31$ CI, 0.107-0.91) Table 3.

Table 2

Associated socio-demographic factors to Stroke knowledge.

\begin{tabular}{|c|c|c|c|c|c|c|}
\hline \multirow[t]{2}{*}{ Variables } & & \multicolumn{5}{|c|}{ Level of Knowledge $(\mathrm{N}=382)$} \\
\hline & & Good & Poor & COR $(95 \% \mathrm{CI})$ & AOR $(95 \% \mathrm{CI})$ & P-Value \\
\hline \multirow[t]{2}{*}{ Sex } & Male & 66 & 134 & 1 & & \\
\hline & Female & 74 & 108 & $1.39(0.95-2.11)$ & $1.64(0.94-2.87)$ & 0.080 \\
\hline \multirow[t]{2}{*}{ Age } & $<50$ years & 96 & 117 & $2.33(1.51-3.61) * *$ & $1.80(1.06-3.05) *$ & 0.031 \\
\hline & $\geq 50$ years & 44 & 125 & 1 & & \\
\hline \multirow[t]{2}{*}{ Residency } & Urban & 128 & 133 & $8.74(4.59-16.64) * *$ & $4.54(2.23-9.25) * *$ & 0.000 \\
\hline & Rural & 12 & 109 & 1 & 1 & \\
\hline \multirow[t]{3}{*}{ Religion } & Orthodox & 86 & 155 & $1.08(0.60-1.95)$ & & \\
\hline & Muslim & 33 & 46 & $1.40(0.70-2.79)$ & & \\
\hline & Protestant & 21 & 41 & 1 & & \\
\hline \multirow[t]{4}{*}{ Marital status } & Single & 29 & 39 & 1 & & \\
\hline & Married & 81 & 156 & $0.7(0.40-1.21)$ & & \\
\hline & Divorced & 19 & 23 & $1.11(0.51-2.41)$ & & \\
\hline & Windowed & 11 & 24 & $0.62(0.26-1.46)$ & & \\
\hline \multirow[t]{2}{*}{ Educational Status } & Unable to read and write & 20 & 116 & 1 & 1 & \\
\hline & Able to read and write & 120 & 126 & $5.52(3.23-9.4) * *$ & $2.78(1.45-5.31) * *$ & 0.002 \\
\hline \multirow[t]{2}{*}{ Monthly Income (Birr) } & $\leq 3000$ & 66 & 174 & 1 & 1 & \\
\hline & $>3000$ & 74 & 68 & $2.87(1.86-4.43) * *$ & $1.98(1.15-3.40)$ * & 0.013 \\
\hline \multirow[t]{6}{*}{ Occupation } & Gov't employee & 48 & 48 & $1.42(0.61-3.28)$ & $1.10(0.42-2.90)$ & 0.844 \\
\hline & House wife & 26 & 42 & $0.88(0.36-2.13)$ & $1.23(0.41-3.67)$ & 0.708 \\
\hline & Farmer & 7 & 67 & $0.15(0.05-0.43)^{* *}$ & $0.30(0.09-1.04)$ & 0.058 \\
\hline & Private Employee & 15 & 22 & $0.97(0.36-2.59)$ & $1.39(0.45-4.32)$ & 0.569 \\
\hline & Merchant & 32 & 46 & $0.985(0.41-2.34)$ & $0.89(0.335-2.35)$ & 0.810 \\
\hline & Others & 12 & 17 & 1 & 1 & \\
\hline \multirow[t]{3}{*}{ Medical condition } & HTN & 24 & 49 & $0.67(0.38-1.25)$ & $0.98(0.47-2.04)$ & 0.965 \\
\hline & $\mathrm{DM}$ & 61 & 116 & $0.74(0.46-1.17)$ & $1.07(0.60-1.92)$ & 0.812 \\
\hline & HTN and DM & 55 & 77 & 1 & 1 & \\
\hline \multirow[t]{2}{*}{ Duration of the disease } & $\leq 5$ years & 41 & 138 & 1 & 1 & \\
\hline & $>5$ Years & 99 & 104 & $3.2(2.05-5.00)^{* *}$ & $1.94(1.15-3.27)^{*}$ & 0.013 \\
\hline
\end{tabular}

Note: 1 , reference group; * statistically significant $\mathrm{P}<0.05$; ** $\mathrm{p}<0.01=$ strongly significant.

Abbreviations: AOR, Adjusted odds ratio: COR, crude odds ratio; CI, Confidence interval; DM, Diabetic mellitus; HTN, Hypertension; Gov't, government. Variables having $\mathrm{P} \leq 0.2$ in bi-variable analysis processed in the multivariable (adjusted) analysis. 


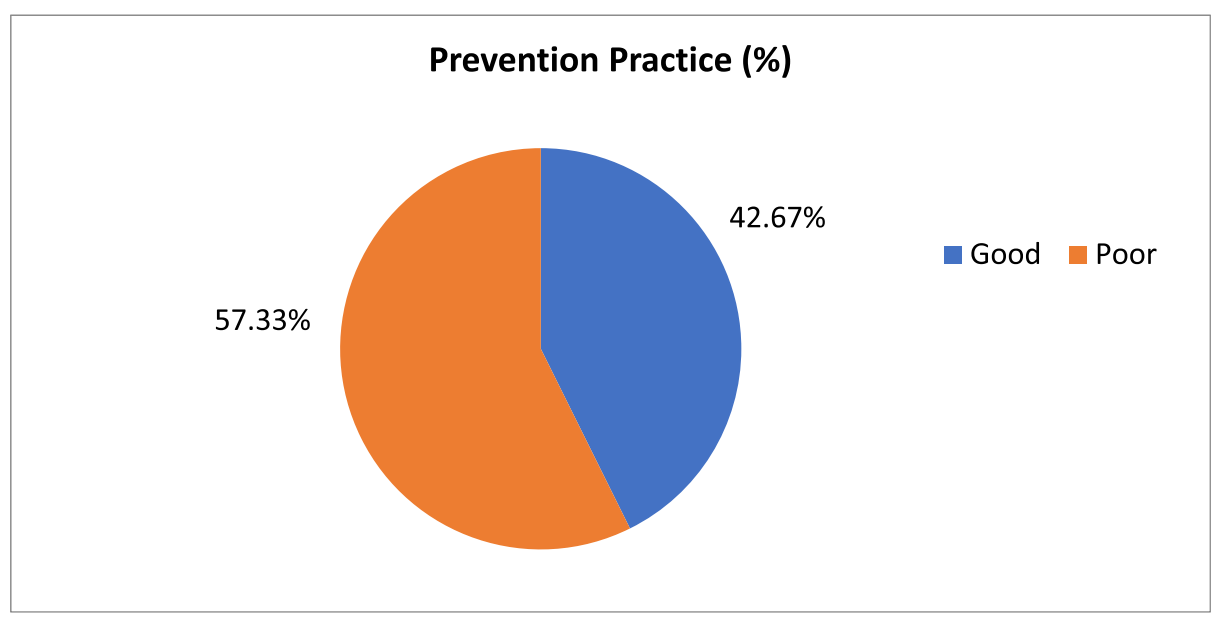

Fig. 2. Level of prevention practice of stroke.

Table 3

Associated demographic factors to the prevention practice of stroke.

\begin{tabular}{|c|c|c|c|c|c|c|}
\hline \multirow[t]{2}{*}{ Variables } & & \multicolumn{5}{|c|}{ Level of Knowledge $(\mathrm{N}=382)$} \\
\hline & & Good & Poor & COR $(95 \% \mathrm{CI})$ & AOR $(95 \% \mathrm{CI})$ & P-Value \\
\hline \multirow[t]{2}{*}{ Sex } & Male & 85 & 115 & $1.01(0.67-1.52)$ & & \\
\hline & Female & 78 & 104 & 1 & & \\
\hline \multirow[t]{2}{*}{ Age } & $<50$ years & 105 & 108 & $1.86(1.23-2.82)^{* *}$ & $0.61(0.375-1.02)$ & 0.060 \\
\hline & $\geq 50$ years & 58 & 111 & 1 & 1 & \\
\hline \multirow[t]{2}{*}{ Residency } & Urban & 137 & 124 & $4.04(2.46-6.64) * *$ & $1.91(1.06-3.43)$ * & 0.030 \\
\hline & Rural & 26 & 95 & 1 & 1 & \\
\hline \multirow[t]{3}{*}{ Religion } & Orthodox & 99 & 142 & $0.79(0.45-1.39)$ & & \\
\hline & Muslim & 35 & 44 & $0.91(0.46-1.76)$ & & \\
\hline & Protestant & 29 & 33 & 1 & & \\
\hline \multirow[t]{4}{*}{ Marital status } & Single & 28 & 40 & 1 & & \\
\hline & Married & 101 & 136 & $1.06(0.61-1.83)$ & & \\
\hline & Divorced & 24 & 18 & $1.90(0.87-4.15)$ & & \\
\hline & Windowed & 10 & 25 & $0.57(0.24-1.37)$ & & \\
\hline \multirow[t]{2}{*}{ Level of education } & Unable to read and write & 26 & 110 & 1 & 1 & \\
\hline & Able to read and write & 137 & 109 & $5.31(3.24-8.73)^{* *}$ & $2.98(1.67-5.31)^{* * *}$ & 0.000 \\
\hline \multirow[t]{2}{*}{ Monthly Income (Birr) } & $\leq 3000$ & 79 & 161 & 1 & 1 & \\
\hline & $>3000$ & 84 & 58 & $2.95(1.92-4.53)^{* *}$ & $2.00(1.20-3.32) * *$ & 0.007 \\
\hline \multirow[t]{6}{*}{ Occupation } & Gov't employee & 54 & 42 & $0.91(0.39-2.11)$ & $0.67(0.26-1.73)$ & 0.414 \\
\hline & House wife & 26 & 42 & $0.43(0.18-1.06)$ & $0.60(0.22-1.63)$ & 0.317 \\
\hline & Farmer & 14 & 60 & $0.16(0.06-0.42)^{* *}$ & $0.31(0.107-0.91)$ * & 0.032 \\
\hline & Private Employee & 18 & 19 & $0.67(0.25-1.78)$ & $0.85(0.28-2.56)$ & 0.777 \\
\hline & Merchant & 34 & 44 & $0.54(0.23-1.29)$ & $0.48(0.187-2.56)$ & 0.133 \\
\hline & Others & 17 & 12 & 1 & 1 & \\
\hline \multirow[t]{3}{*}{ Medical condition } & HTN & 23 & 50 & $0.79(0.44-1.41)$ & $0.75(0.39-1.43)$ & 0.382 \\
\hline & HTN with DM & 75 & 57 & $2.27(1.43-3.59) * *$ & $2.068(1.20-3.57) * *$ & 0.009 \\
\hline & $\mathrm{DM}$ & 75 & 112 & 1 & 1 & \\
\hline \multirow[t]{2}{*}{ Duration of the disease } & $\leq 5$ years & 55 & 124 & 1 & 1 & \\
\hline & $>5$ Years & 108 & 95 & $2.56(1.68-3.90) *$ * & $1.43(0.88-2.33)$ & 0.151 \\
\hline
\end{tabular}

Note: 1 , reference group; * statistically significant $\mathrm{P}<0.05 ; * * \mathrm{p}<0.01=$ strongly significant.

Abbreviations: AOR, Adjusted odds ratio: COR, crude odds ratio; CI, Confidence interval; DM, Diabetic mellitus; HTN, Hypertension; Gov't, government.

Variables having a $(\mathrm{P} \leq 0.2)$ in bi-variable analysis processed in the multivariable (adjusted) analysis.

\section{Discussion}

Stroke has been one of the emerging cerebrovascular diseases becoming a major public health problem in developing countries including Ethiopia. ${ }^{25}$ The high risky individuals like hypertensive and diabetics should be well informed about stroke: the sign and symptoms, risk factors, and prevention strategies as well. Because increasing awareness about the sign and symptoms promotes people to come earlier to the hospital as if they encountered the warning signs of stroke. Knowing the risk factors also enhances them to reduce the triggering factors. Alternatively, being familiar with the prevention strategies is important for the early prevention of stroke. That's why we aimed to assess the level of knowledge and prevention practice among these risky individuals.

The study found that the level of knowledge and prevention practice of the hypertensive and diabetic patients towards stroke have been low. In this finding $36.65 \%$ overall good knowledge of stroke has been found which is in line with the previous study. ${ }^{26}$ But it is less than the previous study done in Nigeria (70\%), ${ }^{26}$ and Ghana (79.18\%). ${ }^{26}$

Despite recent advances in stroke therapy, the majority of stroke patients do not seek immediate medical attention. ${ }^{27}$ Even in developed countries like $\mathrm{UK}^{28}$ and France, ${ }^{29}$ and USA. ${ }^{27,30}$ Knowledge to the warning sign and symptoms of stroke is necessary to enhance the need for rapid medical calls. This is because not identifying the early warning signs leads to a pre-hospital delayed. The main reason for stroke victims too late hospital presentation is considered as their inability to recognize 
the symptoms of stroke, waiting for the sign to abate by itself, and eventually lack of awareness of the advantages that could be obtained from early treatment of thrombolysis. The present study depicted that around $32 \%$ of the study subjects were familiar with the warning sign of stroke. This is almost too low as compared with the previous study done in Nigeria (87\%). ${ }^{26}$ This could be due to the difference in the study population.

Creating awareness regarding the risk factors of stroke is advantageous to improve the trend of abstaining from those contributing lifestyle risk factors. Thus, our study found that only $41.72 \%$ of the subjects were with good knowledge to the risk factors of stroke. Though these subjects were at high risk of stroke, $61.59 \%$ of them were at poor knowledge to the prevention strategies of stroke. This is comparable with a study done in Debre Tabor. ${ }^{31}$ This indicates that there is a limitation to access information regarding to stroke.

The multivariate regression analysis shows that there were some predicting socio-demographic factors associated with stroke knowledge. In this study younger subjects ( $<50$ years) were 1.91 times more likely to be knowledgeable than elderly patients. Thus, it is in line with a study done in Nigerian. ${ }^{32}$ This could be due to the fact that younger subjects can access information from different sources like social media.

Additionally, urban residency, educated subjects, and those with high monthly income were positively associated with good stroke knowledge. The finding is similar to other studies. ${ }^{32,33}$ The possible reason could be the accessibility of information from various sources in these subjects. So far respondents having a disease for more than 5 years were 1.94 times more likely to be knowledgeable. This could be due to the fact that long-time exposure to the disease may get more information through time courses. This is also in line with a previous study. ${ }^{31}$

Furthermore, prevention practice of stroke was positively associated with urban residents, education, and high monthly income. This is due to the fact urban resident, educated and economical subjects have a better chance to come across considerable information on the disease from different sources. This is consistent with a study done in South Ethiopia. $^{34}$

Moreover, a medical condition having both hypertension and diabetes mellitus were 2.068 times more practicing to prevent a stroke than the patients having diabetes solely. This could be due to mindset fear of late complications of the two diseases. In contrast, respondents with farmer occupation were negatively associated with the prevention practice of stroke. This is due to the fact that most farmers are rural residents so that they may not access enough information on how to modify their lifestyle.

\section{Limitation of the study}

In this study, the small sample size was limited which might affect the generalizability of the result. Additionally, since the data was collected via self-report from the participants; there may be the denial of poor knowledge and practices in the respondents, which affects the result of the study. The study also didn't consider other risky populations other than hypertensive and diabetics so that we recommend additional studies to be conducted in the future.

\section{Conclusion and recommendation}

Findings from this study show that the hypertensive and diabetic patients' level of knowledge towards stroke seems to be inadequate. This Inadequate level of knowledge was associated with socio-demographic variables like elderly, educationally low, economically poor, rural residents, and short duration of illness ( $\leq 5$ years). Similarly, the level of prevention practice to prevent stroke is associated with urban residency, educational status, monthly income, occupation (farmer), and medical condition. The possible reason may be the accessibility matter of information sources between these populations. Therefore, we recommend health education to be held to provide adequate information to these risky individuals.

\section{Ethical consideration}

The school of Pharmacy on behalf of the University of Gondar institutional ethical review committee provided ethical clearance (Ref. No.: SOP/262/2013). Upon this clearance, additional written informed consent was taken with included study subjects before the interview. Confidentiality of information was maintained by avoiding the recording of patients' names and keeping the data anonymous. Finally, personal identifiers were excluded during the data presentation.

\section{Availability of data and materials}

Most of the data is included in the manuscript. Additional can be found from the corresponding author based on reasonable request.

\section{Funding}

No funding to report.

\section{Declaration of competing interest}

The authors declare that he has no competing interests.

\section{Acknowledgment}

We would like to acknowledge University of Gondar for material supports.

\section{Abbreviations}

AHA American Heart Association

CACC Chronic Ambulatory Care Clinic

CT Computed Tomography

CV Cerebrovascular

DALYS Disability Adjusted Life Years

DM Diabetic Mellitus

HTN Hypertension

MRI Magnetic Resonance Imaging

NHTN Non-Hypertensive

SSA Sub-Saharan African

WHO World Health Organization

\section{References}

1 Sacco RL, Kasner SE, et al. AHA/ASA expert consensus an updated definition of stroke for the 21st century. Stroke. 2013;44:2064-2089.

2 Mozaffarian D, Benjamin E, Go A, et al. Heart disease and stroke statistics-2016 update: a report from the American Heart Association. Circulation. 2016;133(4):e38.

3 Namale G, Kamacooko O, Kinengyere A, et al. Risk factors for hemorrhagic and ischemic stroke in sub-Saharan Africa. J Trop Med. 2018;2018.

4 Zhang F-L, Guo Z-N, Wu Y-H, et al. Prevalence of stroke and associated risk factors: a population based cross sectional study from northeast China. BMJ Open. 2017;7(9), e015758.

5 Deresse B, Shaweno D. Epidemiology and in-hospital outcome of stroke in South Ethiopia. J Neurol Sci. 2015;355(1-2):138-142.

6 Fekadu G, Chelkeba L, Kebede A. Risk factors, clinical presentations and predictors of stroke among adult patients admitted to stroke unit of Jimma university medical center, south west Ethiopia: prospective observational study. BMC Neurol. 2019;19 (1):183.

7 Kayode-Iyasere E, Odiase FE. Awareness of stroke, its warning signs, and risk factors in the community: a study from the urban population of Benin City, Nigeria. Sahel Med J. 2019;22(3):134.

8 Owolabi MO, Sarfo F, Akinyemi R, et al. Dominant modifiable risk factors for stroke in Ghana and Nigeria (SIREN): a case-control study. Lancet Global Health. 2018;6(4); e436-e446.

9 Habibi-koolaee M, Shahmoradi L, Niakan Kalhori SR, Ghannadan H, Younesi E. Prevalence of stroke risk factors and their distribution based on stroke subtypes in Gorgan: a retrospective hospital-based study_2015-2016. Neurol Res Int. 2018;2018.

10 Powers WJ, Rabinstein AA, Ackerson T, et al. Guidelines for the early management of patients with acute ischemic stroke: 2019 update to the 2018 guidelines for the early 
management of acute ischemic stroke: a guideline for healthcare professionals from the American Heart Association/American Stroke Association. Stroke. 2019;50(12): e344-e418.

11 Hemphill III JC, Greenberg SM, Anderson CS, et al. Guidelines for the management of spontaneous intracerebral hemorrhage: a guideline for healthcare professionals from the American Heart Association/American Stroke Association. Stroke. 2015;46(7): 2032-2060.

12 Alberts MJ. Improving public education about stroke. Ann N Y Acad Sci. 2012;1268 (1):45-50.

13 Feigin VL, Nichols E, Alam T, et al. Global, regional, and national burden of neurological disorders, 1990-2016: a systematic analysis for the Global Burden of Disease Study 2016. Lancet Neurol. 2019;18(5):459-480.

14 WHO. The Top 10 Causes Of Death; 2016. Available from https://www.who.int/news -room/fact-sheets/detail/the-top-10-causes-of-death.

15 Onwuegbuzie GA, Reng RS. Diabetes as a risk factor for ischemic stroke in a tertiary health care center, Abuja. New Niger J Clin Res. 2018;7(11):16.

16 Owolabi L, Nagode M, Ibrahim A, Uloko A, Gezawa I, Datti M. Stroke in patients with diabetes mellitus: a study from North Western Nigeria. Afr Health Sci. 2016;16(3): $781-789$.

17 Saeedi P, Petersohn I, Salpea P, et al. Global and regional diabetes prevalence estimates for 2019 and projections for 2030 and 2045: results from the international diabetes federation diabetes Atlas. Diabetes Res Clin Pract. 2019;157, 107843.

18 Fekadu G, Adola B, Mosisa G, Shibiru T, Chelkeba L. Clinical characteristics and treatment outcomes among stroke patients hospitalized to Nekemte referral hospital, western Ethiopia. J Clin Neurosci. 2020;71:170-176.

19 Gebreyohannes EA, Bhagavathula AS, Abebe TB, Seid MA, Haile KT. In-hospital mortality among ischemic stroke patients in Gondar University Hospital: a retrospective cohort study. Stroke Res Treat. 2019;2019.

20 Colberg SR, Sigal RJ, Yardley JE, et al. Physical activity/exercise and diabetes: a position statement of the American Diabetes Association. Diabetes Care. 2016;39(11): 2065-2079.

21 Eckel RH, Jakicic JM, Ard JD, et al. AHA/ACC guideline on lifestyle management to reduce cardiovascular risk: a report of the American college of cardiology/American heart association task force on practice guidelines. J Am Coll Cardiol. 2013;63(25 Part B):2960-2984, 2014.
22 Food M, Administration HC, CAo Ethiopia. Standard Treatment Guidelines for General Hospitals. 2014.

23 Association AD. 5. Lifestyle management: standards of medical care in diabetes-2019. Diabetes Care. 2019;42(Supplement 1):S46-S60.

24 Organization WH. Guideline: Sodium Intake for Adults and Children. World Health Organization; 2012.

25 Ali S, Misganaw A, Worku A, et al. The burden of cardiovascular diseases in Ethiopia from 1990 to 2017: evidence from the Global Burden of Disease Study. Int Health. 2021;13(4):318-326

26 Weltermann BM, Driouach-Bleckmann Y, Reinders S, Berndt P, Gesenhues S. Stroke knowledge among diabetics: a cross-sectional study on the influence of age, gender, education, and migration status. BMC Neurol. 2013;13(1):202.

27 Williams LS, Bruno A, Rouch D, Marriott DJ, MAS. Stroke patients' knowledge of stroke: influence on time to presentation. Stroke. 1997;28(5):912-915.

28 Carroll C, Hobart J, Fox C, Teare L, Gibson J. Stroke in Devon: knowledge was good, but action was poor. J Neurol Neurosurg Psychiatr. 2004;75(4):567-571.

29 Derex L, Adeleine P, Nighoghossian N, Honnorat J, Trouillas P. Knowledge about stroke in patients admitted in a French Stroke Unit. Rev Neurol. 2004;160(3): 331-337.

30 Kothari R, Sauerbeck L, Jauch E, et al. Patients' awareness of stroke signs, symptoms, and risk factors. Stroke. 1997;28(10):1871-1875.

31 Tibebu NS, Emiru TD, Tiruneh CM, Nigat AB, Abate MW, Demelash AT. Knowledge on prevention of stroke and its associated factors among hypertensive patients at Debre tabor general hospital: an institution-based cross-sectional study. Risk Manag Healthc Pol. 2021;14:1681.

32 Arisegi SA, Awosan KJ, Oche MO, Sabir AA, Ibrahim MT. Knowledge and practices related to stroke prevention among hypertensive and diabetic patients attending Specialist Hospital, Sokoto, Nigeria. Pan Afr Med J. 2018;29(1):1-17.

33 Buda ES, Hanfore LK, Fite RO, Buda AS. Lifestyle modification practice and associated factors among diagnosed hypertensive patients in selected hospitals, South Ethiopia. Clin Hypertens. 2017;23(1):26.

34 Buda ES, Hanfore LK, Fite RO, Buda AS. Lifestyle modification practice and associated factors among diagnosed hypertensive patients in selected hospitals, South Ethiopia. Clin Hypertens. 2017;23(1):1-9. 